\title{
Movimento da pesquisa qualitativa no Brasil: legado do professor Joel Martins
}

\author{
Movement of qualitative research in Brazil: teacher Joel Martins legacy
}

Movimiento de la investigación cualitativa en Brasil: el legado del profesor Joel Martins

\author{
MARIA APARECIDA Viggiani BICUdo ${ }^{1}$ \\ Universidade Estadual Paulista “Júlio de Mesquita Filho", UNESP, Rio Claro-SP, Brasil
}

\begin{abstract}
RESUMO
Este artigo relata sobre o movimento da pesquisa qualitativa que assume a visão de mundo e de conhecimento da fenomenologia, na área da Psicologia e na área da Educação. São expostos os primeiros passos dados pelo Professor Joel Martins, cuja formação, enquanto pesquisador, havia se dado no campo da psicologia experimental, em direção à mudança de seu olhar para outro modo de investigar questões pertinentes ao humano e à sua educação. A importância desse professor é enfatizada no panorama da pesquisa qualitativa fenomenológica no Brasil. São relatados os movimentos de criação de grupos de estudos em fenomenologia, de sociedades de pesquisa qualitativa e mencionadas as produções, advindas desses estudos e investigações. São apontados estudos a serem realizados.
\end{abstract}

Palavras-chave: Pesquisa Qualitativa. Fenomenologia. Educação. Psicologia.

\begin{abstract}
This article is about the movement of qualitative research that assumes the world vision of phenomenology, in the area of Psychology and Education. Are exposed the first steps taken by Professor Joel Martins whose formation as a researcher had taken place in the field of experimental psychology, shifting his gaze to another way of investigating issues pertaining to the human and his education. The importance of this teacher in the panorama of qualitative - phenomenological research in Brazil is emphasized. The movements of creation of study groups in phenomenology, of qualitative research societies are reported and the productions from these studies and investigations are mentioned. Studies are presented that will be performed.
\end{abstract}

Keywords: Qualitative Research. Phenomenology. Education. Psychology.

\section{RESUMEN}

Este artículo informa sobre el movimiento de la investigación cualitativa que toma la visión del mundo y el conocimiento de la fenomenología, en el área de la psicología y en el área de la educación. Son presentados los primeros pasos dados por el Profesor Joel Martins, cuya formación, como investigador, se había llevado a cabo en el campo de la psicología experimental, moviendo su mirada hacia otra forma de investigar temas pertinentes al ser humano y su educación. La importancia de este profesor se enfatiza en el panorama de la investigación cualitativa - fenomenológica en Brasil. Se informan los movimientos de creación de grupos de estudio en fenomenología, de sociedades de investigación cualitativa y se mencionan las producciones de estos estudios e investigaciones. Se señala que se deben realizar estudios.

Palabras clave: Investigación Cualitativa. Fenomenología. Educación. Psicología.

\footnotetext{
${ }^{1}$ Presidente da Sociedade de Estudos e Pesquisa Qualitativos; Pesquisadora 1-A do CNPq. Professora Titular de Filosofia da Educação (aposentada) da UNESP-IGCE. Professora do Programa de Pós-Graduação em Educação Matemática da UNESP-IGCE. E-mail: mariabicudo@gmail.com
} 


\section{SOBRE ESTE ARTIGO}

Trago aos leitores um pouco do movimento da Pesquisa Qualitativa no Brasil, que assume a perspectiva fenomenológica, focando o núcleo de trabalho do Professor Joel Martins $^{2}$. Esse movimento se dá ao longo da trajetória investigativa, vivenciada por ele, ao sabor de: desapontamentos, obstáculos, sentimento de impotência em relação à impossibilidade de se realizarem metas, busca pelo rigor e pelo conhecimento não apenas reproduzido, mas se dando no dinamismo do enfrentamento das adversidades, das perguntas postas e das trilhas seguidas para compreendê-las. Movimento esse entrelaçado aos encontros havidos com pessoas significativas que, de algum modo, abriram caminho para esclarecimentos e para mais buscas, bem como, ao próprio cotidiano histórico-político do seu tempo vivido.

Em entrevista concedida à Silva, em $1991^{3}$, o Professor Joel afirma que, ao realizar o curso de Filosofia na Universidade de São Paulo (USP), estudou com professores franceses renomados como Lévy-Strauss, os quais excitavam o seu pensar, pois falavam do que ele não sabia. Afirma que o curso de Antropologia, conduzido pelo citado professor, abriu-lhe a perspectiva antropológica da educação, levando-o a pensar em uma educação para o mundo tropical. Deixa claro que, a partir do fim do curso normal, quando se assumiu como professor, o mote propulsor de sua realização foi o pensar filosófico da aprendizagem e da educação.

Esse o fio condutor que tece a rede das articulações de sua história e do seu legado a nós, que realizamos pesquisa qualitativa, segundo a visão fenomenológica. Esse o motivo que me leva a trazê-lo nesse artigo para mostrar caminhos que se abriram com nossas realizações, tendo como fundo esse legado. Com esse objetivo, vou trazer a trajetória que percorreu e que o conduziu à fenomenologia e à pesquisa qualitativa.

Inicialmente, desvenda-se para ele o mundo do educador, conforme suas próprias palavras no depoimento dado à Silva, quando, depois de terminar o curso Normal na escola Caetano de Campos, foi trabalhar com crianças carentes da zona rural. Ao trabalhar com essas crianças, deu-se conta da responsabilidade do educador, ao olhar para a vida das pessoas com quem estava trabalhando. Deu-se conta, também, do vazio existente entre essa realidade em que vivia com seus alunos e aquela da estrutura do poder da educação.

Bicudo e Espósito (2002, p. 183) afirmam:

Essa clareza define sua trajetória profissional. Oscila entre atuações em esferas onde pode trabalhar com o poder na Educação, como é o caso de sua entrada no departamento da Educação da Secretaria da Educação do Estado de São Paulo, por volta de 1940-1942, ou ao assumir postos na UNESCO e na OEA, no início da década de sessenta e ao ocupar posições de chefia em centros de pesquisa, escolas, universidades e ao atuar como professor e orientador de pesquisa.

\footnotetext{
${ }^{2}$ Nasceu em 27/03/1920 e faleceu em 02/05/1993. Formou-se na Escola Normal Caetano de Campos. Graduou-se, bacharel e licenciado, em Pedagogia e em Filosofia pela Universidade de São Paulo. Cursou o mestrado nos Estados Unidos da América (EUA) entre 1949 e 1950 e doutorou-se em Psicologia da Educação pela Universidade de São Paulo. Cursou Pós-doutorado na Universidade de Michigan, Ann Arbour, nos EUA, entre 1953 e 1954. Lecionou em Escolas Públicas do Estado de São Paulo nos três diferentes níveis; um dos idealizadores da Pós-Graduação em Educação no Brasil; trabalhou em importantes órgãos internacionais na área da Educação: UNESCO - 1959, OEA - 1960 (BICUDO; ESPÓSITO, 2002).

${ }^{3}$ Entrevista concedida à Sonia Aparecida Inácio da Silva, em 15/10/1991 e em 13/11/1991, pelo Professor Joel Martins.
} 
Dado seu modo de ser inquieto, irreverente, questionador e reflexivo e ao compreender-se impotente para transformar a estrutura de poder com a qual se deparava naquele Departamento de Educação do Estado de São Paulo que, posteriormente, transformou-se em Secretaria da Educação desse mesmo Estado, busca seguir estudos na Faculdade de Filosofia, Ciências e Letras da Universidade de São Paulo, cursando os cursos de Filosofia e de Pedagogia, como já mencionado nesse artigo.

Da Filosofia, segue o desafio de pensar as questões concernentes ao conhecimento e ao humano. Da Pedagogia, a perseguição pelo entendimento da aprendizagem, interessando-se, então pela pesquisa empírica. Depois de terminar o Mestrado nos Estados Unidos, é contratado como auxiliar da Professora Noemy Silveira Rudolfer, na Cadeira de Psicologia da Aprendizagem, na mesma universidade onde realizou a graduação em Pedagogia. Aí, buscou avançar com os estudos em aprendizagem, realizando o doutorado. Mas, conforme suas palavras ${ }^{4}$ se sentiu desapontado do início ao fim, pois não havia sequer um laboratório em que se fizessem pesquisas experimentais com ratos em situação de escolha de alternativas. Partiu para a Universidade de Michigan, nos Estados Unidos da América, onde se dedicou à investigação da Teoria da Aprendizagem de Clark Hull. Sua pesquisa se constitui em desenvolver o postulado número nove dessa teoria, concernente à motivação. Nesse trabalho, aprendeu sobre o rigor do método. Entretanto, mesmo observando todos os passos da pesquisa experimental, e sua hipótese quase comprovada estatisticamente, o sujeito (o rato) invertia a resposta e desorganizava a experiência.

Essa ocorrência o coloca em busca de respostas à pergunta: por que ocorre esse tipo de comportamento do sujeito? Seu desassossego o mantém em estado de alerta. Na entrevista concedida à Silva, em 1991, afirma que o artigo $O$ comportamento do rato em ponto de escolha, de Tollman Hall, levou-o a ir conversar com esse autor. Relata que, ao indagar sobre o porquê de o rato ter comportado daquele modo no experimento que estava desenvolvendo, Tollamn Hall olhou-o bem e disse: por que o senhor não se coloca no lugar do rato? Dá-se, conforme entendo, a mudança do seu olhar. Não visa mais à ciência naturalista em sua objetividade, mas busca outro ponto de vista. Qual? Adentrou pela Psicologia cognitiva, estudando os construtivistas. Mas as suas interrogações ainda se mantinham vivas e solicitando buscas. Já no final da década de 1960, como professor na Pontifícia Universidade Católica de São Paulo (PUCSP), ele começa a se interessar por fenomenologia, quando se encontra com a Professora Maria Fernanda S. Farinha Beirão Dichtchekenian, em cuja pesquisa de doutorado estudava Edmund Husserl.

Em entrevista concedida pela Professora Dichtchekenian, em $1993^{5}$, ela relata que foi conversar com o Joel por indicação do seu então orientador. Menciona que, nesse encontro, ele se mostrou bastante animado e interessado pelo assunto que estava estudando, pois queria encontrar um método fenomenológico, alternativo ao experimental.

Nesse período, por suas mãos, as questões ontológicas são trazidas para a Psicologia da Aprendizagem e para a Educação, agora olhadas da perspectiva da fenomenologia. Na PUCSP, formam-se grupos para estudar as obras de Husserl, os quais deram origem ao Centro de Estudos Fenomenológicos de São Paulo.

\footnotetext{
${ }^{4}$ Depoimento dado à Silva, em 1991.

5 Em 1993, as Professoras Dra. Marília Marino, Dra. Verilda Speridião Kluth e Ms. Lourdes Lucia Ribeiro realizaram entrevistas em nome da Sociedade de Estudos e Pesquisa Qualitativos, dentre as quais com a Professora Maria Fernanda S. Farinha Beirão Dichtchekenian.
} 


\section{AS DÉCADAS DE 1970 E DE 1980}

As críticas de Edmund Husserl à psicologia empírica e à ciência vão sendo compreendidas e dão sustentação às discussões que se seguiram, pelas décadas de 1970 e de 1980. Nessas décadas, as disciplinas lecionadas pelo Professor Joel, no âmbito da Pós-Graduação da PUCSP, são realizadas como se fossem seminários. Eram momentos de discussões e de abertura às leituras de autores ainda não muito estudados. Ele manteve sempre a prática de modificar o tratado na disciplina nos diferentes semestres e anos, não se repetindo, focando temas e autores diferenciados, conduzindo as aulas com Notas de Aula. Ele as produzia estudando os textos, traduzindo-os muitas vezes, e organizando os conteúdos em itens enumerados com subitens, datilografadas por ele mesmo e distribuídas entre os presentes a cada aula (encontros semanais ao longo de cada semestre). Estes as multiplicavam e as distribuíam. Participavam de suas aulas alunos regulares da Pós-Graduação matriculados na disciplina, ex-alunos, exorientandos, estudantes especiais, pessoas diversas interessadas. Ou seja, seus cursos eram abertos.

Os estudos realizados, tanto nas aulas da Pós-Graduação em Educação (Currículo) como também do grupo de estudos do Centro de Estudos Fenomenológicos de São Paulo, versavam sobre Fenomenologia, focando autores como Edmund Husserl, Martin Heideigger, Maurice Merleau-Ponty e Paul Ricoeur, buscando aberturas para compreenderem-se a ciência e sua lógica, bem como procedimentos metodológicos e tecendo articulações com a Educação e com a Psicologia, primeiramente, e com outras áreas pela demanda dos próprios orientandos e ex-orientandos do Professor Joel, tais como Educação Física, Enfermagem, Matemática. As reuniões do grupo eram quinzenais e ocorriam nas dependências da PUCSP, campus da Rua Monte Alegre, em São Paulo, no bairro das Perdizes. Elas foram se sistematizando pela década de 1980 e nutridas pelas aulas desse professor.

As leituras e as discussões conduziam os integrantes do grupo - sempre aberto aos que quisessem dele participar - a irem além do posto, articulando temas diferenciados e aprofundando questões da filosofia e da própria ciência, da educação, da psicologia; enfim, da própria problemática do humano.

O modo de ser inquieto do Professor Joel, sua força e sua visão, foi trazendo a ideia de criação de uma Sociedade, que se deu em 1989, sendo denominada Sociedade de Estudos e Pesquisa Qualitativos (SE\&PQ). Quando essa ideia ganhou maior definição, todo o grupo que com ele estava não mediu esforços para a criação e a manutenção dessa Sociedade. Em seu Estatuto constituinte estava determinado que fossem produzidos, semestralmente, artigos e livros decorrentes dos estudos e das pesquisas realizadas.

O Professor Joel mantinha ligações próximas com o Professor Amedeo Giorgi ${ }^{6}$ que vem da psicologia experimental e também trilhou caminhos para mudar a

\footnotetext{
6 "Nos últimos cinquenta anos, Amedeo Giorgi desempenhou um papel de liderança no movimento para redirecionar a pesquisa psicológica da imitação das ciências naturais para o paradigma da ciência humana. Ele fundou o primeiro programa de pesquisa psicológica fenomenológica nos Estados Unidos, na Universidade de Duquesne, e continuou desenvolver a psicologia fenomenológica na Saybrook Graduate School. O método fenomenológico descritivo de Giorgi é uma abordagem rigorosa da pesquisa qualitativa, fundada na filosofia fenomenológica de Edmund Husserl e Maurice Merleau-Ponty. O método fenomenológico descritivo trabalha com a epoché, com a redução, com a variação imaginativa fenomenológicas em busca de estruturas psicológicas essenciais. A abordagem de Giorgi para trazer a fenomenologia à psicologia apresenta uma crítica abrangente e incisiva das limitações da psicologia empírica e procura estabelecer critérios científicos apropriados para o estudo do programa de pesquisa
} 
concepção da Psicologia vista como ciência da saúde e definida por métodos experimentais, para a Psicologia vista e tratada como ciência humana.

Nas décadas aqui mencionadas, ambos se dedicaram a construir um método para a realização de pesquisas qualitativas, segundo a visão fenomenológica, tomando as descrições obtidas de entrevistas, de relatos de ocorrências, de estudos de casos clínicos como dados a serem analisados e interpretados.

O Professor Amedeo Giorgi produziu muitos livros e artigos, dentre os quais cito alguns que estão na raiz desse movimento (GIORGI, 1970; 2009). O Professor Joel Martins produziu mais de 400 Notas de Aulas distribuídas pelos seus muitos alunos e seguidores e não sistematizadas. Dentre os títulos publicados, são bastante conhecidos $A$ Pesquisa Qualitativa em Psicologia (MARTINS; BICUDO, 1989), que traz uma sistematização inicial de seus ensinamentos sobre a pesquisa qualitativa fenomenológica, e Estudos Sobre Existencialismo, Fenomenologia e Educação (MARTINS; BICUDO, 2006 - $2^{\mathrm{a}}$ edição). Com Amedeo Giorgi, os procedimentos versavam sobre fenomenologia estrutural. Com Maria Fernanda S. Farinha Beirão Dichtchekeniam, organizou Temas Fundamentais de Fenomenologia (MARTINS; DICHTCHEKENIAN, 1984).

A sistematização realizada é, como o nome retrata, uma sistematização, porque não dá conta de toda a profundidade das discussões e da diversidade de procedimentos que se abriram com os estudos de Martin Heidegger e de Paul Ricoeur, avançando por análises hermenêuticas.

Nessas décadas, a pesquisa qualitativa toma corpo e são publicados livros importantes como os de Guba e Lincoln (1989), Lincoln e Guba (1985), Bogdan e Biklen (1982), Lüdke e André (1986).

Conforme meu entendimento, assumindo-me neste agora do meu tempo vivenciado e buscando no fluxo da lembrança das ocorrências das quais participei direta ou indiretamente, o diferencial dos estudos sobre pesquisa qualitativa, realizados pelo grupo conduzido pelo professor Joel, incide nos estudos da fenomenologia, vista como filosofia, e a busca por procedimentos de pesquisa consonantes com a filosofia fenomenológica.

\section{A forÇa/fraqueza da Sociedade de Estudos e Pesquisa Qualitativos - SE\&PQ}

O Professor Joel, com seu modo de ser inquieto e sua força e visão, junto com as pessoas que com ele estavam presentes às reuniões de estudo, foi expondo e amadurecendo a ideia da criação de uma Sociedade. Quando essa ideia ganhou maior definição, todo o grupo que com ele estava, não mediu esforços para a criação e para a manutenção dessa Sociedade. Em seu Estatuto constituinte, estava determinado que fossem produzidos, semestralmente, material de estudos e de pesquisas. Foram criados os Cadernos de Pesquisa com a publicação de três números; organizados livros ${ }^{7}$; defendidos Mestrados e Doutorados; apresentados trabalhos em congressos diversos e, ainda, realizados congressos ${ }^{8}$.

psicológica fenomenológica da subjetividade humana vivida” (APPLEBAUM, 2011, p. 518 - tradução livre).

${ }^{7}$ Os cadernos e os livros produzidos estão à disposição para download no site da Sociedade de Estudos e Pesquisa Qualitativos: www.sepq.org.br

${ }^{8}$ O SIPEQ - Seminário Internacional de Estudos e Pesquisa Qualitativos, com sua primeira versão em 2001, e a quinta e mais recente, em 2018. 
A $\mathrm{SE}_{\mathrm{P}} \mathrm{PQ}^{9}$ foi constituída com base no grupo que estudava fenomenologia e realizava investigações qualitativas da perspectiva dessa filosofia o que the rendeu louros e decorrências nefastas. Entendo que os louros têm muito a ver com o próprio estudo da fenomenologia e as aberturas propiciadas a respeito da visão de ciência, de sua constituição e produção e da compreensão do humano. Por outro lado, pesquisadores das áreas de Educação e de Ciências Humanas, em geral, viram-na tão somente como dedicada à fenomenologia, buscando outros núcleos em que pudessem apresentar seus estudos realizados de acordo com outras vertentes da pesquisa qualitativa. Com isso, embora a Sociedade, desde seu início, tenha sido pensada como nucleadora de diferentes abordagens, ela não se realizou desse modo. Sua manutenção enfrentou muitas dificuldades, em virtude do baixo número de associados para financeiramente sustentá-la. Em alguns períodos, ficou em estado latente e em outros, mais atuante. A morte do Professor Joel, em 1993, afastou muitas pessoas, porém um pequeno grupo manteve-se unido e atuante.

Conforme exposto no site da sociedade, entre 1990 e 1991, foram publicados três números dos Cadernos de Pesquisa Qualitativa, à disposição para consulta, contendo relatos de pesquisas nas áreas de ciências humanas. Com o falecimento do Professor Joel, a publicação dos Cadernos foi interrompida. Em 1994, a Professora Dra. Marília J. Marino ministrou um Seminário de 32 horas intitulado A Existência Segundo o Pensamento de Martin Heidegger - Abordagem Sócio-psicodramática. Nesse mesmo ano, resultante de minicurso oferecido pela SE\&PQ, no II Congresso Paulista sobre Formação de Professores, realizado em Águas de São Pedro, a SE\&PQ publica o livro Pesquisa Qualitativa em Educação (BICUDO; ESPÓSITO, 1994).

No interstício desse período, 1991 a 1994, os sócios buscaram outros espaços de divulgação. Em 1991, foi publicado o livro Currículo, um enfoque fenomenológico: educação como poiésis (MARTINS, 1991). Em 1993, a Professora Vitória H. C. Espósito publicou A escola: um enfoque fenomenológico (ESPÓSITO, 1993). Em 1996, foi publicado, pela mesma professora, o livro Pedagogo artesão - construindo a trama no cotidiano da escola (MARTINS; ESPÓSITO, 1996). Em 1997, foi publicado Joel Martins... um seminário avançado em fenomenologia (BICUDO; ESPÓSITO, 1997), composto por notas de aulas da disciplina que o Professor Dr. Joel Martins estava ministrando na Pós-Graduação em Educação (Currículo), da PUCSP, em 1993, até maio, quando ele falece, e que foram retomadas e reescritas por membros da sociedade que continuaram a disciplina até o seu final.

Nessa época, os membros da SE\&PQ se propuseram a trazer a presença do professor, pesquisador e administrador universitário Joel Martins, por meio de entrevistas realizadas com pessoas significativas da comunidade universitária e que com

\footnotetext{
${ }^{9}$ Sociedade de Estudos e Pesquisa Qualitativos foi constituída em 27/03/1989, em reunião presidida pela Professora Dra. Maria Aparecida Viggiani Bicudo e secretariada pela Professora Dra. Vitória Helena Cunha Espósito. Surge em torno das ideias educacionais e das ideias de pesquisa do Professor Dr. Joel Martins, seu primeiro Presidente, e de seus ex-alunos e orientandos. Desenvolve-se, no decorrer do tempo, à medida que o trabalho desses profissionais ganha espaço e credibilidade, agregando outros pesquisadores, prevista, quanto aos encontros associativos, em suas diversas modalidades. A sociedade tem, desde sua fundação, a finalidade de desenvolver: estudos avançados em pesquisa qualitativa; publicar trabalhos apresentados; divulgar, nacional e internacionalmente, os resultados dos estudos e das pesquisas realizadas em uma abordagem qualitativa; capacitar pesquisadores em pesquisa qualitativa; e congregar pesquisadores que investigam de acordo com procedimentos da pesquisa qualitativa. Ao longo destes anos, tem cumprido suas finalidades, embora nem sempre tenha sido possível manter a frequência inicialmente prevista (Disponível em: www.sepq.org.br - Acesso em: 4 ago. 2019)
} 
ele tinham desenvolvido projetos. Esses depoimentos foram analisados e organizados, subsidiando o artigo Joel Martins: a coragem de ser educador (BICUDO, 2002).

Em 1999, foram lançados os livros: Fenomenologia: uma visão abrangente da educação (BICUDO; CAPPELLLETTI, 1999). Formação de educadores: pesquisa e estudos qualitativos (CAPPELLETTI; LIMA, 1999), e Eu, um quadrado? (ESPÓSITO, 1999). Em 2001, o livro Fenomenologia: confrontos e avanços (BICUDO, 2001).

Intercalando as atividades acima citadas, a Sociedade, até o final de 2001, promoveu reuniões mensais com o objetivo de efetuar estudos avançados sobre temas pertinentes a essa modalidade de pesquisa e para a discussão e a apreciação de textos escritos pelos sócios. Esse foi o critério adotado, então, para permitir que os trabalhos fossem publicados em nome da SE\&PQ e, posteriormente, apresentados em nome da mesma sociedade.

De setembro de 2001 até a atualidade, a SE\&PQ vem organizando o Seminário Internacional de Estudo e Pesquisa Qualitativos (SIPEQ), já tendo realizado cinco edições. Em 2008, foi realizado o I Encontro de Representantes de grupo de Pesquisa e Estudos Qualitativos (ERPEQ), na PUCSP, atividade importante, porém ocorreu apenas a citada edição.

De 2010 a 2015, a SE\&PQ passou por um período de dificuldades desencadeadas por uma multiplicidade de ocorrências. A Diretoria, então à frente da Sociedade, envidou esforços para mantê-la. Graças a esse esforço, em 2015, houve possibilidade de as atividades da Sociedade de Estudos e Pesquisa Qualitativos serem reiniciadas. Em 2016, a Revista Pesquisa Qualitativa ${ }^{10}$ (ISSN: 2525-8222), criada em 2005, foi retomada, passando a ser publicada digitalmente. Em 2019, é publicado o livro Leituras em pesquisa qualitativa (BICUDO; COSTA, 2019).

Hoje, com muito esforço, tem trazido pesquisadores que trabalham com outras vertentes e atuantes em diferentes áreas das ciências: exatas, humanas, da saúde, esforçando- se por reunir diferentes entidades que realizam investigação qualitativa.

\section{Destacando o legado de Joel Martins: olhando para o Meu entorno PRÓXIMO}

Os estudos, orientados pelo Professor Joel Martins, ao incidirem sobre obras de Edmund Husserl, Martin Heidegger, Maurice Merleau-Ponty e Paul Ricoeur, contribuíram para que toda uma geração que esteve em suas aulas e em grupos de estudos/pesquisas nas décadas de 1970, 1980 e início dos anos de 1990, adentrasse por questões sobre: o humano, a educação, a constituição e produção do conhecimento, a realidade, o cotidiano vivenciado em diferentes situações, questões de rigor e de procedimentos ao se realizar investigação qualitativa. A lista de temas enlaçados por esses estudos é ampla e se desdobra, à medida que as pessoas presentes na rede, em movimento, colocam suas interrogações, trazem consigo a historicidade de sua formação e com elas avançam pelos caminhos da investigação.

Como está explicitado neste item, falarei desse legado, olhando para o meu entorno próximo, focando aquele de que posso falar com maior propriedade, uma vez que se refere ao grupo de pesquisa que coordeno. Trago esse grupo por isso e também por entendê-lo fundamental, à medida que trabalha com a Matemática e com a Educação Matemática, áreas diferentes daquelas pertinentes, inicialmente, ao núcleo de interesse do Professor Joel: as questões sobre o humano e a psicologia da aprendizagem.

10 A partir de 2016, a Revista Pesquisa Qualitativa é disponibilizada on-line: https://editora.sepq.org.br/index.php/rpq/ 
Coordeno o Grupo de Estudos denominado Fenomenologia em Educação Matemática $(\mathrm{FEM})^{11}$. Os estudos das obras de Edmund Husserl foram abrindo possibilidades para a discussão sobre a ciência, dando destaque às visões e aos respectivos procedimentos consonantes à filosofia positivista, considerando sua hegemonia nos meios científicos e acadêmicos e o que então, na década de 1980, era denominado de modos alternativos de conceber e fazer ciência. A questão que se colocava para nós era compreender o que significavam essas discussões para a Ciência Matemática, para o fazer matemático e para a Educação Matemática. Do mesmo modo, os procedimentos de pesquisa qualitativa fenomenológica demandaram estudos para entendermos sua contribuição para pesquisa em Educação Matemática.

A caminhada vem se alongando desde 1984, quando se iniciou o Programa de Pós-Graduação em Educação Matemática, na Universidade Estadual Paulista (UNESP), campus de Rio Claro, onde sou professora e orientadora. Foram orientadas dissertações e teses, que têm pavimentado esse percurso. Ex-orientandos orientam e trabalham também nessa direção. Um dos produtos importantes, conforme meu entendimento, tem sido a compreensão da Matemática que a nós tem se aberto com os estudos das obras de Husserl. Temos publicado - aqui falo dos membros do grupo, tomado em sua totalidade - trabalhos em Filosofia da Matemática e em Filosofia da Educação Matemática. Esses estudos demandam que se foque, inclusive, a constituição do conhecimento e sua produção que, com Husserl, entendemos solicitarem investigações a respeito do corpopróprio, da percepção, da linguagem, da intropatia, da história. Esse trabalho pode ser visto nos site em que são expostas as dissertações e teses ${ }^{12}$ e o site onde são arrolados os trabalhos do FEM.

Minha intenção, com o anteriormente exposto, é enfatizar o legado de todo o trabalho do Professor Joel e mostrar os caminhos para onde está nos conduzindo.

Do mesmo modo, vejo o trabalho realizado pelo Professor Luiz Gonçalves Junior, da Universidade Federal de São Carlos, em uma vertente diferente, iniciado em um momento posterior ao do FEM, dada a diferença de gerações que há entre nós. Ele também estudou com o Professor Joel, que o orientou em seu Mestrado. Já não pôde contar com essa orientação em seu doutorado, decorrente do falecimento do Professor Joel, mas carregou consigo o legado, na direção apontada pelos estudos da obra de Maurice Merleau-Ponty, notadamente, nas questões concernentes à Motricidade Humana.

$\mathrm{Na}$ universidade em que trabalha, vem também realizando estudos em grupo de pesquisa denominado Núcleo de Estudos de Fenomenologia em Educação Física $(\mathrm{NEFEF})^{13}$, fundado em 1996, com a meta de questionar a própria Educação Física. Tem buscado ir além do discurso explícito e aceito pelos estudiosos e práticos dessa disciplina, ao olhá-la da perspectiva da Fenomenologia, inclusive defendendo uso da denominação Motricidade Humana, para a área. À medida que seus estudos avançaram e o grupo se fortaleceu, foi criada a Sociedade de Pesquisa Qualitativa em Motricidade Humana (SPQMH) ${ }^{14}$, fundada em 13 de junho de 2003. Os esforços de suas atividades se materializam na criação e manutenção dessa sociedade, na orientação de dissertações e de teses, na realização de congressos, entre eles o Colóquio de Pesquisa Qualitativa

\footnotetext{
${ }^{11}$ Disponível em: www.sepq.org.br/fem - Acesso em: 04 ago. 2019.

${ }^{12}$ Disponível em: www.mariabicudo.org.br - Acesso em: 04 ago. 2019.

${ }^{13}$ Disponível em: http://www.motricidades.org/spqmh/nefef/ - Acesso em: 04 ago. 2019.

${ }^{14}$ Disponível em: http://www.motricidades.org/spqmh/ - Acesso em: 04 ago. 2019.
} 
em Motricidade Humana (CPQMH) ${ }^{15}$, já em sua oitava edição, e na criação da Revista Motricidades $^{16}$ (ISSN: 2594-6463), editada pela SPQMH.

\section{O QUE SE ESTÁ POR FAZER}

Trouxe dois exemplos de desdobramentos do legado que Joel Martins nos deixou. Todavia, considero indispensável para o fortalecimento da pesquisa qualitativa e, notadamente, daquela que assume a fenomenologia, que seja realizado um trabalho de mapeamento dos núcleos que se formaram. Temos conhecimento da forte presença desse modo de investigar na Enfermagem, na Educação Matemática e na Educação Física (Motricidade Humana), por exemplo. E na Educação? E na Psicologia? E na Psiquiatria? Onde estão atuando esses núcleos, o que interrogam, o que estão produzindo, como percebem o sentido do seu trabalho para as comunidades onde atuam?

${ }^{15}$ Disponível em: http://www.motricidades.org/conference/index.php - Acesso em: 04 ago. 2019.

${ }^{16}$ Disponível em: http://www.motricidades.org/journal/index.php/journal - Acesso em: 04 ago. 2019. 
Maria Aparecida Viggiani Bicudo

\section{REFERÊNCIAS}

APPLEBAUM, M. Amedeo Giorgi and psychology as a human science. NeuroQuantology, v. 9, n. 3, p. 518-525, 2011.

BICUDO, M. A. V. Fenomenologia: confrontos e avanços. São Paulo: Cortez, 2001.

BICUDO, M. A. V.; CAPPELlLETTI, I. (Orgs.). Fenomenologia: uma visão abrangente da educação. São Paulo: Olho D'Água, 1999.

BICUDO, M. A. V.; COSTA, A. P. Leituras em pesquisa qualitativa. São Paulo: Livraria da Física, 2019.

BICUDO, M. A. V.; ESPÓSITO, V. H. C. Joel Martins: a coragem de ser educador. In: GARCIA, W. E. (Org.). Educadores brasileiros do século XX. Brasília: Editora Brasília, 2002. p. 173-200.

BICUDO, M. A. V.; ESPÓSITO, V. H. C. (Orgs.). Joel Martins... um seminário avançado em fenomenologia. São Paulo: EDUC/ PUCSP, 1997.

BICUDO, M. A. V.; ESPÓSITO, V. H. C. Pesquisa qualitativa em educação. Piracicaba: Editora UNIMEP, 1994.

BOGDAN, R.; BIKLEN, S. K. (Orgs.). Qualitative research for education. Boston: Allyn and Bacon, 1982.

CAPPELlETTI, I.; LIMA, L. A. N. (Orgs.). Formação de educadores: pesquisa e estudos qualitativos. São Paulo: Olho D'Água, 1999.

ESPÓSITO, V. H. C. Eu, um quadrado? São Paulo: Artes e Ciências. 1999.

ESPÓSITO, V. H. C. A escola: um enfoque fenomenológico. São Paulo: Escrita, 1993.

GIORGI, A. The descriptive phenomenological method in psychology. Pittsburgh: Duquesne University Press, 2009.

GIORGI, A. Psychology as a human science. New York: Harper \& Row, 1970.

GUBA, E. G.; LINCOLN, Y. S. Fourth generation evaluation. London: Sage Publications, 1989.

LINCOLN, Y. S.; GUBA, E. G. Naturalistic inquiry. London: Sage Publications, 1985.

LÜDKE, M.; ANDRÉ, M. E. D. A. Pesquisa em educação: abordagens qualitativas. São Paulo: EPU, 1986.

MARTINS, J. Currículo, um enfoque fenomenológico: educação como poiésis. São Paulo: Cortez, 1991.

MARTINS, J.; BICUDO, M.A.V. Estudos sobre existencialismo, fenomenologia e educação. 2. ed. São Paulo: Centauro, 2006.

MARTINS, J.; BICUDO, M. A. V. A pesquisa qualitativa em psicologia: fundamentos e recursos básicos. São Paulo: Moraes/ EDUC, 1989.

MARTINS, J.; DICHTCHEKENIAN, M. F. S. B. (Orgs.). Temas fundamentais de fenomenologia. São Paulo: Moraes, 1984.

MARTINS, M. A. V.; ESPÓSITO, V. H. C. Pedagogo artesão: construindo a trama no cotidiano da escola. São Paulo: EDUC, 1996.

Recebido em: 27 ago. 2019.

Aprovado em: 12 set. 2019.

Motricidades: Rev. SPQMH, v. 3, n. 2, p. 141-150, maio-ago. 2019 | ISSN 2594-6463 |

DOI: http://dx.doi.org/10.29181/2594-6463.2019.v3.n2.p141-150 